\title{
re University Association for Emergency Medicine
}

Sir

At the Annual Meeting earlier this spring, the University Association for Emergency Medicine (UAEM) identified as one of its priorities for the coming -year the establishment and development of ties with other national and internationa organizations and individuals interested and involved in emergency medicine research.

The membership of this organization is comprised of individuals from varied backgrounds - surgery, anaesthesia, critical care, paediatrics, internal medicine ando emergency medicine. Although diverse in background, they have been drawn togetherby their interest in the acutely ill and injured individual.

There have been significant developments in emergency medicine in many countriesw around the world these past few years. Despite this 'coming of age' of the specialty, there apparently exists no forum for the dissemination of research in our specialty at an. international level. There are a number of international societies in critical care and $\overrightarrow{\phi_{A}}$ anaesthesia which address many of those issues which involve emergency medicine (viz resuscitation, etc.). However, it is the intention of UAEM to form an internationab forum specific to the needs and interests of emergency medicine. Although there is overlap between many of the traditional specialties in emergency medicine, the focus of UAEM is to promote research in the early evaluation and management of the emergency patient.

UAEM sponsors a number of activities, including an annual meeting at which this year 100 research papers in the field of emergency medicine were presented. It af $\overrightarrow{000}$ hosts a yearly state of the art Symposium and is the co-sponsor of the Annals Emergency Medicine. With membership of UAEM a free subscription is provided to theु journal and a 'no-attendance fee' for its Annual Meeting.

I am writing to enquire as to whether anyone might be interested in joining UAEM and participating in its activities. At present there are but 30 non North American $\frac{\circ}{\mathbb{D}}$ members of the Society but it is hoped that the international membership will grow $\stackrel{\varrho}{\Rightarrow}$ substantially in the next few years, and with it, greater dissemination of research in $\frac{0}{3}$ emergency medicine at an international level.

\section{B. M. T. ROWAT}

Chairman

University Association for Emergency Medicine

Committee on International Affairs

Correspondence: Dr B. M. T. Rowat, Toronto General Hospital, 101 College Street, Toronto, Ontario, 응 Canada, M5G 1L7 